\title{
Modular Battery Management System for Power Electronics Practical Laboratory Lessons
}

\author{
José Cabrera Peña, Samuel Ortega, Eduardo Quevedo, Himar Fabelo, Gustavo M Callico \\ Institute for Applied Microelectronics \\ University of Las Palmas de Gran Canaria \\ Las Palmas de Gran Canaria, Spain \\ jcabrera@iuma.ulpgc.es, sortega@iuma.ulpgc.es, equevedo@iuma.ulpgc.es, hfabelo@iuma.ulpgc.es, gustavo@iuma.ulpgc.es
}

\begin{abstract}
Current engineering bachelor degrees usually suffer from a lack of finalist content, and also a suitable orientation to the real practical professional activities. This work addresses the implementation of a project-based methodology using a fully functional modular battery management system (BMS) for "Power Electronics" practical laboratory lessons, combining the knowledge and specifications of three related subjects taught in the last course of "Automatic and Electronic Industrial Engineering" bachelor degree.
\end{abstract}

Keywords- Power Electronics, Converters, Controllers, Inverters, Practical bachelor teaching 